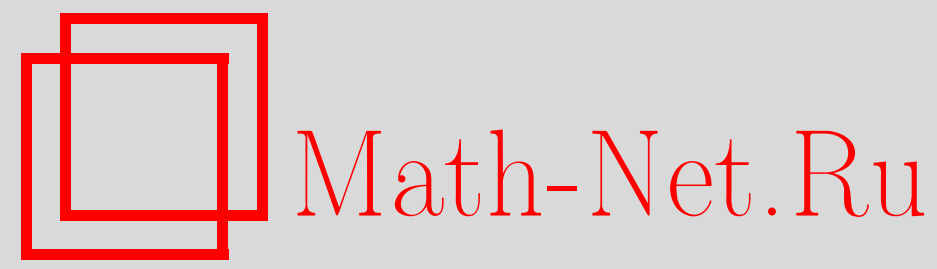

I. Klein, W. Schachermayer, Asymptotic arbitrage in noncomplete large financial markets, Теория вероятн. и ее примен., 1996, том 41, выпуск 4, 927-934

DOI: https://doi.org/10.4213/tvp3284

Использование Общероссийского математического портала Math-Net.Ru подразумевает, что вы прочитали и согласны с пользовательским соглашением http://www.mathnet.ru/rus/agreement

Параметры загрузки:

IP : 34.239 .49 .27

26 апреля 2023 г., 04:47:01

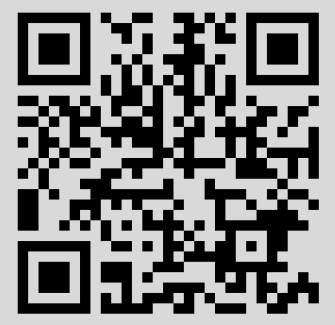




\section{ASYMPTOTIC ARBITRAGE IN NON-COMPLETE LARGE FINANCIAL MARKETS}

Ю. М. Кабанов и Д. О. Крамков ввели понятие «больших финансовых рынков». Вместо того, чтобы рассматривать -- как это обычно делается в финансовой математике - некоторый случайный процесс $S$ цен акций, заданный на фильтрованном вероятностном пространстве $\left(\Omega, \mathcal{F},\left(\mathcal{F}_{t}\right)_{t \in I}, \mathbf{P}\right)$, они рассматривали последовательность $\left(S^{n}\right)_{n} \geqslant 1$ таких процессов, заданную на последовательности $\left(\Omega^{n}, \mathcal{F}^{n},\left(\mathcal{F}_{i}^{n}\right)_{t \in I^{n}}, \mathbf{P}^{n}\right)_{n} \geqslant 1$ фильтрованных вероятностных пространств. Такая модель оправдывается тем, что инвестор может делать вклады не на одной, а на нескольких фондовых биржах (в модели Кабанова и Крамкова - на счетном числе).

Привычное понятие арбитража тогда можно интерпретировать с помошью понятий асимптотического арбитража, где важно различать между собой два рода асимптотического арбитража, введенные Кабановым и Крамковым. В случае, когда для каждого $n \in \mathbf{N}$ рынок полон (т.е. существует единственная «локально мартингальная》 мера $Q^{n}$ для процесса $S^{n}$ на $\mathcal{F}^{n}$, эквивалентная $\mathbf{P}^{n}$ ), Кабанов и Крамков показали, что контигуальность $\left(\mathbf{P}^{n}\right)_{n} \geqslant 1$ относительно $\left(Q^{n}\right)_{n} \geqslant 1$ (соответственно, наоборот) эквивалентна отсутствию асимптотического арбитража первого (соответственно, второго) рода.

В настоящей статье мы распространяем этот результат на случай неполного рынка, когда для каждого $n \in \mathbf{N}$ множество эквивалентных локально мартингальных мер непусто, но не обязательно одноэлементно. Возникает вопрос, можно ли перенести на этот случай теорему Кабанова и Крамкова, выбирая подходящую последовательность $\left(Q^{n}\right)_{n} \geqslant_{1}$ эквивалентных локально мартингальных мер.

Оказывается, что в части, характеризующей асимптотический арбитраж первого рода, теорема может быть жепосредственно перенесена на этот случай, однако в части, характеризующей асимптотический арбитраж второго рода, необходимы некоторые изменения: Мы также строим пример, показываюший, что этих измёнений нельзя избежать.

Ключевые слова и Фразы: арбитраж, асимптотический арбитраж, контигуальность мер, эквивалентная мартингальная мера, «бесплатный завтрак», «бесплатный завтрак с исчезаюше малым риском», большие финансовые рынки.

Introduction. In this paper we deal with arbitrage possibilities in a large financial market, a concept originally introduced by Kabanov and Kramkov, see [10]. Following these authors we define a large financial market to be a sequence of filtered probability spaces $\left(\Omega^{n}, \mathcal{F}^{n},\left(\mathcal{F}_{t}^{n}\right)_{t \in \mathbf{R}_{+}}, \mathbf{P}^{n}\right)$. On each of these "small" spaces we can trade in $d(n)$ securities, whose price processes are denoted by an $\mathbf{R}^{d(n)}$-valued $\left(\mathcal{F}_{t}^{n}\right)$-adapted semimartingale.

We suppose that for each "small market" there exists a probability measure $Q^{n}$ on $\mathcal{F}^{n}$ that is equivalent to the original measure $\mathbf{P}^{n}$, such that $S^{n}$ is a local $Q^{n}$-martingale. So we obviously do not have any arbitrage opportunities on the small markets, a fact that is very well-known (see [8]; [9]). Nevertheless by choosing a reasonably large portfolio (i.e., by trading on a large number of small markets) we may be able to make some kind of approximation of an arbitrage profit. Kabanov and Kramkov called this form of arbitrage an asymptotic arbitrage and distinguished two kinds. Asymptotic arbitrage of first kind (see Definition 1.1 below) can be interpreted as an opportunity of getting arbitrarily rich with positive probability by risking arbitrarily small losses, i.e., taking a

*Institut für Statistik, Brünnerstraße 72, A-1210 Wien, Austria. 
"vanishing risk" (compare the notion of "no free lunch with vanishing risk", introduced in [4]). Asymptotic arbitrage of second kind (see Definition 1.2 below) describes the possibility of gaining something with probability arbitrarily close to 1 , but by taking the risk of loosing a uniformly bounded amount of money (say for example one ECU), i.e., one has the chance of a very likely profit but only with bounded (not vanishing) risk. So the difference between the two kinds of asymptotic arbitrage is that on one hand by risking nearly nothing we can become very rich but onfy on a set of positive probability, on the other hand we can win something, maybe very little, with very high probability, but there is the possibility to loose one ECU on a set of probability nearly zero.

In the "classical" case where we do not have a sequence of financial markets but only one fixed market there has been done a lot of work relating the absence of arbitrage or similar concepts (such as "no free lunch" [11], "no free lunch with bounded risk" [2], [12], "no free lunch with vanishing risk" [4]) to the existence of an equivalent local martingale measure for the price process of the available securities, e.g. [2], [4], [6], [8], [9], [11]-[13]. In a large financial market there is a similar situation. We will specify conditions on the local martingale measures of the small spaces, respectively on sequences of such measures, that are necessary and sufficient for the absence of asymptotic arbitrage of first or second kind.

Kabanov and Kramkov already presented such conditions but only for the special case when the set of equivalent local martingale measures for each small space (denoted by $\mathcal{M}^{e}\left(\mathbf{P}^{n}\right)$ ) consists of a single $Q^{n}$ (for each $n$ ). The notion of contiguity of sequences of probability measures, a concept often used in mathematical statistics, plays an important role. Kabanov and Kramkov showed that $\left(\mathbf{P}^{n}\right)_{n \geqslant 1}$ is contiguous with respect to $\left(Q^{n}\right)_{n} \geqslant 1$, respectively $\left(Q^{n}\right)_{n} \geqslant 1$ contiguous with respect to $\left(\mathbf{P}^{n}\right)_{n \geqslant 1}$, if and only if there is no asymptotic arbitrage of first kind, respectively second kind. For the general case $\left(\mathcal{M}^{e}\left(\mathbf{P}^{n}\right)\right.$ is not a singleton) Kabanov and Kramkov proved the sufficiency: the existence of some sequence $\left(Q^{n}\right)_{n \geqslant 1}, Q^{n} \in \mathcal{M}^{e}\left(\mathbf{P}^{n}\right)$, with the respective contiguity property implies the absence of asymptotic arbitrage of the respective kind.

We generalize these results to the case where $\mathcal{M}^{e}\left(\mathbf{P}^{n}\right)$ is not necessarily a singleton and observe an interesting asymmetry. For the case of asymptotic arbitrage of first kind we show that the result of Kabanov and Kramkov remains valid (i.e., we prove the necessity of the above condition). In the other case we have to modify the condition on the equivalent local martingale measures and thus establish a condition that is necessary and sufficient for the absence of asymptotic arbitrage of second kind. For the case where $\mathcal{M}^{e}\left(\mathbf{P}^{n}\right)$ is a singleton this condition equals the contiguity condition of Kabanov and Kramkov. But we present a counterexample where $\mathcal{M}^{e}\left(\mathbf{P}^{n}\right)$ is not a singleton showing that in this case the necessity of the contiguity condition fails.

1. Definitions and notation. Let $\left(B^{n}\right)_{n=1}^{\infty}=\left(\Omega^{n}, \mathcal{F}^{n},\left(\mathcal{F}_{t}^{n}\right)_{t \in \mathbf{R}_{+}}, \mathbf{P}^{n}\right)_{n=1}^{\infty}$ be a sequence of filtered probability spaces where the filtration satisfies the usual conditions. For $n \in \mathbf{N}$ let $S^{n}=\left(S_{t}^{n}\right)_{t \in \mathbf{R}_{+}}$be a locally bounded $\left(\mathcal{F}_{t}^{n}\right)$-adapted semimartingale on $B^{n}$ with values in $\mathbf{R}^{d(n)}$, describing the (discounted) price of $d(n)$ available securities. We choose the time set to be $\mathbf{R}_{+}$to cover the most general case.

We define $\mathcal{M}\left(\mathbf{P}^{n}\right)=\left\{Q^{n} \ll \mathbf{P}^{n}, S^{n}\right.$ is local $Q^{n}$-martingale $\}$ to be the set of all absolutely continuous local martingale measures for the process $S^{n}$ and $\mathcal{M}^{e}\left(\mathbf{P}^{n}\right)=\left\{Q^{n} \in\right.$ $\left.\mathcal{M}\left(\mathbf{P}^{n}\right) \mid Q^{n} \sim \mathbf{P}^{n}\right\}$ the set of the equivalent ones. As in [10] we assume that for any $n: \mathcal{M}^{e}\left(\mathbf{P}^{n}\right) \neq \varnothing$; in particular it is no restriction at all to require $S^{n}$ to be a càdlàg semimartingale. Moreover on each fixed probability space $B^{n}$ any condition of no-arbitrage-type is satisfied.

A trading strategy on $B^{n}$ will be an $\mathbf{R}^{d(n)}$-valued predictable $S^{n}$-integrable stochastic process $H^{n}=\left(H_{t}^{n}\right)_{t \in \mathbf{R}_{+}}$. The predictability of $H^{n}$ describes mathematically the obvious assumption that one should not be able to foresee the future. We only admit general admissible integrands as trading strategies, i.e., we require that there is $a \in \mathbf{R}_{+}$such that 
for all $n$ and $t$ we have that $\left(H^{n} \cdot S^{n}\right)_{t} \geqslant-a$ almost surely, describing the natural idea that the losses of a portfolio should stay bounded (compare [4]).

As we always require $\mathcal{M}^{e}\left(\mathbf{P}^{n}\right) \neq \varnothing$, whence the admissibility condition on the integrands will imply that, for all $n,\left(H^{n} \cdot S^{n}\right)_{\infty}=\lim _{t \rightarrow \infty}\left(H^{n} \cdot S^{n}\right)_{t}$ exists and is finite a.e. $\left(\left(H^{n} \cdot S^{n}\right)\right.$ is an $L^{1}$-bounded supermartingale for each $\left.Q^{n} \in \mathcal{M}^{e}\left(\mathbf{P}^{n}\right)\right)$. Note that $\left(H^{n} \cdot S^{n}\right)_{t}$ denotes the stochastic integral of $H^{n}$ with respect to $S^{n}$ at time $t$ and describes the cumulated gains or losses according to the strategy $H^{n}$ until time $t$.

We reformulate the notions of Asymptotic Arbitrage of first and second kind (AA1, $\mathrm{AA2}$ ), see [10].

$\mathrm{D}$ e $\mathrm{f} \mathrm{i}$ i t i o $\mathrm{n}$ 1.1. A sequence $\left(H^{n}\right)_{n=1}^{\infty}$ of admissible trading strategies realizes asymptotic arbitrage of first kind (AA1), if and only if

(1) $\left(H^{n} \cdot S^{n}\right)_{t} \geqslant-c_{n}$ for all $t \in \mathbf{R}_{+}$, i.e., $H^{n}$ is $c_{n}$-admissible,

(2) $\limsup _{n \rightarrow \infty} \mathbf{P}^{n}\left\{\left(H^{n} \cdot S^{n}\right)_{\infty} \geqslant C_{n}\right\}>0$, where $c_{n}>0$ tend to zero and $C_{n}>0$ to infinity.

AA1 describes the possibility of getting arbitrarily rich with positive probability by taking an arbitrarily small (vanishing) risk.

$\mathrm{D}$ e $\mathrm{f} i \mathrm{n}$ i $\mathrm{t}$ i o $\mathrm{n}$ 1.2. A sequence of admissible trading strategies realizes asymptotic arbitrage of second kind (AA2), if and only if

(1) $\left(H^{n} \cdot S^{n}\right)_{t} \geqslant-1$, for all $t \in \mathbf{R}_{+}$, i.e., $H^{n}$ is 1-admissible,

(2) $\exists c>0$ such that $\limsup _{n \rightarrow \infty} \mathbf{P}^{n}\left\{\left(H^{n} \cdot S^{n}\right)_{\infty} \geqslant c\right\}=1$.

AA2 can be interpreted as an opportunity of gaining something with probability arbitrarily close to one, but by taking a uniformly bounded risk.

A large financial market satisfies No Asymptotic Arbitrage of first, respectively second kind (NAA1, NAA2), if and only if it does not allow the respective arbitrage opportunities.

A sequence of measures $\left(Q^{n}\right)_{n \in \mathbf{N}}$ is called contiguous with respect to $\left(\mathbf{P}^{n}\right)_{n \in \mathbf{N}}$, denoted by $\left(Q^{n}\right)_{n} \geqslant 1 \triangleleft\left(\mathbf{P}^{n}\right)_{n} \geqslant 1$, if and only if for all sequences $\left(A^{n}\right)_{n \in \mathbf{N}}, A^{n} \in \mathcal{F}^{n}$, $\mathbf{P}^{n}\left(A^{n}\right) \rightarrow 0$ implies that $Q^{n}\left(A^{n}\right) \rightarrow 0$.

Kabanov and Kramkov proved the following theorem [10].

Theorem 1.1. Suppose that, for all $n, \mathcal{M}^{e}\left(\mathbf{P}^{n}\right)$ consists of a single measure $Q^{n}$.

(1) $\left(\mathbf{P}^{n}\right)_{n \geqslant 1} \triangleleft\left(Q^{n}\right)_{n \geqslant 1}$ if and only if NAA1 is satisfied.

(2) $\left(Q^{n}\right)_{n \geqslant 1} \triangleleft\left(\mathbf{P}^{n}\right)_{n \geqslant 1}$ if and only if NAA2 is satisfied.

In order to extend this result to the case where $\mathcal{M}^{e}\left(\mathbf{P}^{n}\right)$ is not necessarily a singleton we suppose for the rest of the paper that $\mathcal{M}^{e}\left(\mathbf{P}^{n}\right) \neq \varnothing$, for each $n$, and gather some notatior and results. For each $n$ define

$$
\mathcal{K}^{n}=\left\{\left(H^{n} \cdot S^{n}\right)_{\infty} \mid H^{n} \text { admissible }\right\}
$$

to be the set of all random variables which are outcomes of admissible trading strategies considered as a subset of $L^{0}\left(\Omega^{n}, \mathcal{F}^{n}, \mathbf{P}^{n}\right)$. Let

$$
\mathcal{C}_{0}^{n}=\mathcal{K}^{n}-L_{+}^{0}\left(\Omega^{n}, \mathcal{F}^{n}, \mathbf{P}^{n}\right), \quad \mathcal{C}^{n}=\mathcal{C}_{0}^{n} \cap L^{\infty}\left(\Omega^{n}, \mathcal{F}^{n}, \mathbf{P}^{n}\right)
$$

The next result is in the spirit of a theorem of Yor [14] and is a direct consequence of Theorem 4.2 in [4].

Theorem 1.2. $\mathcal{C}^{n}$ is a weak ${ }^{*}$-closed (i.e., $\sigma\left(L^{\infty}, L^{1}\right)$-closed) cone in $L^{\infty}\left(\Omega^{n}, \mathcal{F}^{n}, \mathbf{P}^{n}\right)$.

The following duality relation between $\mathcal{C}^{n}$ and $\mathcal{M}^{e}\left(\mathbf{P}^{n}\right)$ (see, e.g., [5, Theorem 6]) will be crucial in our treatment as the proof of Theorems 2.1 and 2.2 below will be baseu on Hahn-Banach arguments.

Lemma. An element $g \in L^{1}\left(\Omega^{n}, \mathcal{F}^{n}, \mathbf{P}^{n}\right)$, normalized by $\mathbf{E}_{\mathbf{P}^{n}}(g)=1$, is the density of a measure $Q^{n} \in \mathcal{M}\left(\mathbf{P}^{n}\right)$ if and only if $\mathbf{E}_{\mathbf{P}^{n}}(g h) \leqslant 0$ for all $h \in \mathcal{C}^{n}$.

Similarly an element $h \in L^{\infty}\left(\Omega^{n}, \mathcal{F}^{n}, \mathbf{P}^{n}\right)$ is in $\mathcal{C}^{n}$ if and only if $\mathbf{E}_{Q^{n}}(h) \leqslant 0$ for all $Q^{n} \in \mathcal{M}\left(\mathbf{P}^{n}\right)$ (or equivalently for all $Q^{n} \in \mathcal{M}^{e}\left(\mathbf{P}^{n}\right)$ ).

Finally we need the following result of Ansel and Stricker [1], which essentially goes back to Émery [7]. 
Theorem 1.3. If $M$ is a d-dimensional local martingale, $H$ a d-dimensional admissible integrand for $M$, then $H \cdot M$ is a local martingale and therefore (being bounded from below) a supermartingale.

2. Results. We suppose that $\left(\Omega^{n}, \mathcal{F}^{n},\left(\mathcal{F}_{t}^{n}\right)_{t \in \mathbf{R}_{+}}, \mathbf{P}^{n}\right), S^{n}$ is as stated in Section 1 , in particular that $\mathcal{M}^{e}\left(\mathbf{P}^{n}\right) \neq \varnothing$ for each $n \in \mathbf{N}$.

Theorem 2.1. NAA1 is satisfied if and only if there exists a sequence $\left(Q^{n}\right)_{n} \geqslant 1$, $Q^{n} \in \mathcal{M}^{e}\left(\mathbf{P}^{n}\right)$ for all $n$, such that $\left(\mathbf{P}^{n}\right)_{n \geqslant 1} \triangleleft\left(Q^{n}\right)_{n \geqslant 1}$.

Theorem 2.2. NAA2 is satisfied if and only if for each $\varepsilon>0$ there exist measures $Q^{n} \in \mathcal{M}^{e}\left(\mathrm{P}^{n}\right)$ and $\delta>0$, such that for any set $A^{n} \in \mathcal{F}^{n}$ with $\mathrm{P}^{n}\left(A^{n}\right)<\delta$ we have that $Q^{n}\left(A^{n}\right)<\varepsilon$.

While Theorem 2.1 is a straight generalization of the Kabanov-Kramkov theorem, the necessary and sufficient condition stated in theorem 2.2 is of a somewhat technical nature and reflects an interchange of quantifiers. We do not assert that we may choose a sequence $Q^{n} \in \mathcal{M}^{e}\left(\mathbf{P}^{n}\right)$ such that for each $\varepsilon>0$ there is $\delta>0$ etc. (which would precisely mean that $\left(Q^{n}\right)_{n} \geqslant 1$ is contiguous with respect to $\left.\left(\mathbf{P}^{n}\right)_{n} \geqslant 1\right)$. We only assert that for each $\varepsilon>0$ there is a sequence $\left(Q^{n}\right)_{n} \geqslant 1, Q^{n} \in \mathcal{M}^{e}\left(P^{n}\right)$, (depending on $\varepsilon$ ) such that there is $\delta>0$ etc. Clearly if $\mathcal{M}^{e}\left(\mathbf{P}^{n}\right)$ is reduced to a singleton then the choice of $Q^{n} \in \mathcal{M}^{e}\left(\mathbf{P}^{n}\right)$ cannot depend on $\varepsilon$ and therefore Theorem 2.2 contains the Kabanov-Kramkov theorem as a special case. But the subsequent example shows that this interchange of quantifiers is indeed necessary for Theorem 2.2 to be valid in the present generality.

$\mathrm{E} \times \mathrm{a} \mathrm{m} \mathrm{ple} \mathrm{2.1.} \mathrm{There} \mathrm{is} \mathrm{a} \mathrm{sequence} \mathrm{of} \mathrm{probability} \mathrm{spaces}\left(\Omega^{n}, \mathcal{F}^{n}, \mathbf{P}^{n}\right)$ and $\mathbf{R}^{n}$ valued processes $\left(S_{t}^{n}\right)_{t \in\{0,1\}}$, such that:

(1) NAA2 is satisfied, while

(2) for any sequence $\left(Q^{n}\right)_{n \geqslant 1}, Q^{n} \in \mathcal{M}^{e}\left(\mathbf{P}^{n}\right)$ for all $n$, we have that $\left(Q^{n}\right)_{n \geqslant 1} \nless$ $\left(\mathbf{P}^{n}\right)_{n \geqslant 1}$.

3. Proofs. P r o o f of $\mathrm{Th}$ e o $\mathrm{r}$ e $\mathrm{m}$ 2.1. We just prove the "only if"-part as the "if"-part is proved in Kabanov-Kramkov [10].

So assume that NAA1 is satisfied. We shall construct a sequence $Q^{n} \in \mathcal{M}^{e}\left(\mathbf{P}^{n}\right)$ such that $\left(\mathbf{P}^{n}\right)_{n \geqslant 1} \triangleleft\left(Q^{n}\right)_{n \geqslant 1}$. Let $M \in \mathbf{R}_{+}$and define, for $n \in \mathbf{N}$,

$$
D_{M}^{n}=\left\{h^{n} \in L_{+}^{\infty}\left(\Omega^{n}, \mathcal{F}^{n}, \mathbf{P}^{n}\right) \mid \mathbf{E}_{\mathbf{P} n}\left(h^{n}\right)=1,\left\|h^{n}\right\|_{\infty} \leqslant M\right\} .
$$

Claim. For any $M \geqslant 1$ there exists $\gamma_{M}>0$ such that, for all $n$,

$$
\operatorname{dist}_{\|\cdot\|_{\infty}}\left(\mathcal{C}^{n}, D_{M}^{n}\right) \geqslant 2 \gamma_{M},
$$

where $\mathcal{C}^{n}$ is the set defined in Section 1.

P r o of of $\mathrm{th} \mathrm{e} \mathrm{c} \mathrm{la} \mathrm{i} \mathrm{m.} \mathrm{If} \mathrm{not,} \mathrm{there} \mathrm{exists} M_{0}$ and a sequence $\left(n_{k}\right)_{k=1}^{\infty}$ of positive integer numbers, such that $\operatorname{dist}_{\|\cdot\|_{\infty}}\left(\mathcal{C}^{n_{k}}, D_{M_{0}}^{n_{k}}\right)<1 /\left(4 k^{2}\right)$. That means there exist an admissible integrand $H^{n_{k}}$ and $f^{n_{k}} \in L_{+}^{0}, h^{n_{k}} \in D_{M_{0}}^{n_{k}}$, such that $\|\left(H^{n_{k}} \cdot S^{n_{k}}\right)_{\infty}-$ $f_{n_{k}}-h_{n_{k}} \|_{\infty}<1 /\left(4 k^{2}\right)$, i.e.,

$$
-\frac{1}{4 k^{2}}+f_{n_{k}}+h_{n_{k}}<\left(H^{n_{k}} \cdot S^{n_{k}}\right)_{\infty}<\frac{1}{4 k^{2}}+f_{n_{k}}+h_{n_{k}} \quad \text { a.s. }
$$

Since $f_{n_{k}}, h_{n_{k}}$ are non-negative we have that $\left(H^{n_{k}} \cdot S^{n_{k}}\right)_{\infty} \geqslant-1 /\left(4 k^{2}\right)$ a.e.

Besides that $h^{n_{k}} \in D_{M_{0}}^{n_{k}}$ and therefore $\mathbf{P}^{n_{k}}\left\{h^{n_{k}} \geqslant \frac{1}{2}\right\} \geqslant 1 /\left(2 M_{0}\right)$, and this implies that for all $k$ :

$$
\mathbf{P}^{n_{k}}\left\{\left(H^{n_{k}} \cdot S^{n_{k}}\right)_{\infty} \geqslant \frac{1}{4}\right\} \geqslant \frac{1}{2 M_{0}} .
$$

Now define a new integrand $\widetilde{H}^{n_{k}}:=4 k H^{n_{k}}$. Then we have that

$$
\left(\widetilde{H}^{n_{k}} \cdot S^{n_{k}}\right)_{\infty} \geqslant-\frac{1}{k} \quad \text { a.e. }
$$


As we assume that $\mathcal{M}^{e}\left(\mathbf{P}^{n_{k}}\right) \neq \varnothing$ we have that $\widetilde{H}^{n_{k}}$ is $1 / k$-admissible (see [4, Proposition $3.5])$. On the other hand $\mathbf{P}^{n_{k}}\left\{\left(\widetilde{H}^{n_{k}} \cdot S^{n_{k}}\right)_{\infty} \geqslant k\right\} \geqslant 1 /\left(2 M_{0}\right)$ a.e., so we get an asymptotic arbitrage of first kind, thus proving the claim (*).

Take now $M \geqslant 1$ fixed. By Theorem 1.2 we have that $\mathcal{C}^{n}$ is weak*-closed and $D_{M}^{n}$ is clearly weak*-compact. Hence by Hahn-Banach we can find $g^{n, M} \in L^{1}\left(\mathbf{P}^{n}\right)$, $\left\|g^{n, M}\right\|_{1}=1$, such that,

$$
\sup _{f^{n} \in \mathcal{C}^{n}} \mathbf{E}_{\mathbf{P}^{n}}\left(g^{n, M} f^{n}\right) \leqslant \inf _{h^{n} \in D_{M}^{n}} \mathbf{E}_{\mathbf{P}^{n}}\left(g^{n, M} h^{n}\right)-\gamma_{M}
$$

As $\mathcal{C}^{n}$ is a cone the left-hand side equals zero and $g^{n, M} \geqslant 0$, because $-L_{+}^{\infty} \subseteq \mathcal{C}^{n}$. By Lemma we see that $g^{n, M}$ is the density of a measure in $\mathcal{M}\left(\mathbf{P}^{n}\right)$.

Moreover we have that for any $h^{n} \in D_{M}^{n}$ :

$$
\mathbf{E}_{\mathbf{P} n}\left(g^{n, M} h^{n}\right) \geqslant \gamma_{M}
$$

We claim that this implies that

$$
\mathbf{P}^{n}\left\{g^{n, M}<\gamma_{M}\right\}<\frac{1}{M}
$$

Indeed, suppose $\mathbf{P}^{n}\left\{g^{n, M}<\gamma_{M}\right\}=p \geqslant 1 / M$. Let $h^{n}:=(1 / p) \chi_{\left\{g^{n, M}<\gamma_{M}\right\}}$ which is in $D_{M}^{n}$. Because of (2)

$$
\gamma_{M} \leqslant \mathbf{E}_{\mathbf{P}^{n}}\left(g^{n, M} h^{n}\right)=\frac{1}{p} \mathbf{E}_{\mathbf{P}^{n}}\left\{g^{n, M} \chi_{\left\{g^{n, M}<\gamma_{M}\right\}}\right\}<\gamma_{M},
$$

a contradiction, proving (3).

Let now $M=1,2, \ldots$ and find for each $M \in \mathbf{N}$ the $\gamma_{M}>0$ as above and, for each $n$, the density $g^{n, M}$ of a measure in $\mathcal{M}\left(\mathrm{P}^{n}\right)$ as above. Define

$$
G^{n}:=\sum_{M=1}^{\infty} 2^{-M} g^{n, M},
$$

so that $G^{n}$ is the density of a measure $Q^{n}$ in $\mathcal{M}\left(\mathbf{P}^{n}\right)$, since (by the local-boundedness assumption on $\left.S^{n}\right) \mathcal{M}\left(\mathbf{P}^{n}\right)$ is convex and closed in $L^{1}\left(\mathbf{P}^{n}\right)$. We even have that $Q^{n}$ is in $\mathcal{M}^{e}\left(\mathrm{P}^{n}\right)$, because $\left\{G^{n}=0\right\} \subseteq \bigcap_{M=1}^{\infty}\left\{g^{n, M}<\gamma_{M}\right\}$.

Finally we claim that $\left(\mathbf{P}^{n}\right)_{n \geqslant 1} \triangleleft\left(Q^{n}\right)_{n \geqslant 1}$.

We have to show that, for $\varepsilon>0$, we can find $\delta>0$, such that for $A^{n} \in \mathcal{F}^{n}$ with $Q^{n}\left(A^{n}\right)<\delta$ we have that $\mathbf{P}^{n}\left(A^{n}\right)<\varepsilon$.

Let $\varepsilon>0$. Choose $M$ so that $2 M^{-1}<\varepsilon$ and fix this $M$. Let now $\delta<2^{-M} \gamma_{M} M^{-1}$ and $A^{n} \in \mathcal{F}^{n}$ with $Q^{n}\left(A^{n}\right)<\delta$. We see that

$$
\begin{aligned}
\mathbf{P}^{n}\left(A^{n}\right) & =\mathbf{P}^{n}\left(A^{n} \cap\left\{g^{n, M}<\gamma_{M}\right\}\right)+\mathbf{P}^{n}\left(A^{n} \cap\left\{g^{n, M} \geqslant \gamma_{M}\right\}\right) \\
& \leqslant M^{-1}+\mathbf{P}^{n}\left(A^{n} \cap\left\{G_{n} \geqslant 2^{-M} \gamma_{M}\right\}\right) \\
& \leqslant M^{-1}+\frac{2^{M}}{\gamma_{M}} Q^{n}\left(A^{n}\right)<2 M^{-1}<\varepsilon .
\end{aligned}
$$

So $\left(Q^{n}\right)_{n \geqslant 1} \triangleleft\left(\mathbf{P}^{n}\right)_{n} \geqslant 1$. Theorem 2.1 is proved.

$\mathrm{P}$ r o o f of $\mathrm{T}$ h e o r e $\mathrm{m}$ 2.2. Sufficiency of the $(\varepsilon-\delta)$-condition. Suppose that there is an arbitrage opportunity of second kind, i.e., there is a sequence $\left(H^{n}\right)_{n=1}^{\infty}$ of 1 -admissible integrands and $c>0$ such that

$$
\liminf _{n \rightarrow \infty} \mathbf{P}^{n}\left\{\left(H^{n} \cdot S^{n}\right)_{\infty}<c\right\}=0
$$


Let $\varepsilon>0$ be small enough such that $-\varepsilon+c(1-\varepsilon)>0$ and apply the assumption to find $\delta>0$ and a sequence $Q^{n} \in \mathcal{M}^{e}\left(\mathbf{P}^{n}\right)$ such that, for $A^{n} \in \mathcal{F}^{n}, \mathbf{P}^{n}\left(A^{n}\right)<\delta$, we have that $Q^{n}\left(A^{n}\right)<\varepsilon$. Choose $n$ big enough such that $\mathbf{P}^{n}\left\{\left(H^{n} \cdot S^{n}\right)_{\infty}<c\right\}<\delta$ so that $Q^{n}\left\{\left(H^{n} \cdot S^{n}\right)_{\infty}<c\right\}<\varepsilon$ which implies that $\mathbf{E}_{Q^{n}}\left(\left(H^{n} \cdot S^{n}\right)_{\infty}\right) \geqslant-\varepsilon+c(1-\varepsilon)>0$. On the other hand, as $\left(H^{n} \cdot S^{n}\right)$ is a $Q^{n}$-supermartingale (see Theorem 1.3) $\mathrm{E}_{Q^{n}}\left(\left(H^{n} \cdot S^{n}\right)_{\infty}\right) \leqslant 0$, a contradiction.

Necessity of the $(\varepsilon-\delta)$-condition. Suppose to the contrary that there exists $1>\varepsilon>0$ such that for any $\delta>0$ there is $n \in \mathbf{N}$ such that for each $Q^{n} \in \mathcal{M}^{e}\left(\mathbf{P}^{n}\right)$ there exists a set $A_{Q^{n}} \in \mathcal{F}^{n}$ with $\mathbf{P}^{n}\left(A_{Q^{n}}\right)<\delta$ but $Q^{n}\left(A_{Q^{n}}\right) \geqslant \varepsilon$. Choose a sequence $\delta_{k} \rightarrow 0$ and the corresponding $n_{k}$ as above. Now we construct a sequence of admissible integrands $H^{n_{k}}$ admitting AA2. We do this by constructing $H^{n_{k}}$ for each fixed $k$, so we omit superscripts. Let $\widehat{\mathcal{M}(\mathbf{P})}$ be the cone in $L^{1}(\mathbf{P})$ generated by the densities $d Q / d \mathbf{P}$, where $Q \in \mathcal{M}(\mathbf{P})$, and let

$$
\Gamma:=\left\{g \in L_{+}^{1}(\mathbf{P}),\|g\|_{1}=1, g \leqslant \frac{\varepsilon}{4 \delta} \quad \text { a.s. }\right\} \text {. }
$$

We claim that

$$
\operatorname{dist}_{\|\cdot\|_{1}}(\Gamma, \widehat{\mathcal{M}(\mathbf{P})}) \geqslant \frac{\varepsilon}{4}
$$

We have to show that for all $\lambda \in \mathbf{R}_{+}$

$$
\operatorname{dist}_{\|\cdot\|_{1}}(\Gamma, \lambda \mathcal{M}(\mathbf{P})) \geqslant \frac{\varepsilon}{4}
$$

This is obvious for $\lambda \notin] 1-\varepsilon / 4,1+\varepsilon / 4$ [. So suppose $\lambda \in] 1-\varepsilon / 4,1+\varepsilon / 4$ [. Let $Q$ be a measure in $\mathcal{M}(\mathbf{P}), A_{Q}$ such that $\mathbf{P}\left(A_{Q}\right)<\delta$ and $Q\left(A_{Q}\right) \geqslant \varepsilon$ and $g$ a function in $\Gamma$. Then we have

$$
\left\|\lambda \frac{d Q}{d \mathbf{P}}-g\right\|_{1} \geqslant\left|\mathbf{E}\left(\lambda \frac{d Q}{d \mathbf{P}} \chi_{A_{Q}}\right)-\mathbf{E}\left(g \chi_{A_{Q}}\right)\right| \geqslant\left(1-\frac{\varepsilon}{4}\right) \varepsilon-\frac{\varepsilon}{4 \delta} \delta>\frac{\varepsilon}{4},
$$

whence (4) is proved.

By Hahn-Banach there exists $f \in L^{\infty}(\mathrm{P})$ such that $\|f\|_{\infty}=1$ and

$$
\sup _{h \in \mathcal{M}(\mathbf{P})} \mathbf{E}_{\mathbf{P}}(h f) \leqslant \inf _{g \in \Gamma} \mathbf{E}_{\mathbf{P}}(g f)-\frac{\varepsilon}{4} .
$$

As $\widehat{\mathcal{M ( P})}$ is a cone we may again conclude that the left-hand side equals zero. We deduce from Lemma that $f$ is in $\mathcal{C}$, i.e., there is an admissible integrand $H$, such that

$$
f \leqslant(H \cdot S)_{\infty} .
$$

Clearly $(H \cdot S)_{\infty} \geqslant-1$ whence $H$ is 1 -admissible (cf. again Proposition 3.5 of [4]). Inequality (5) implies that for any $g \in \Gamma$ :

$$
\mathbf{E}_{\mathbf{P}}(g f) \geqslant \frac{\varepsilon}{4}
$$

We claim that

$$
\mathbf{P}\left\{f<\frac{\varepsilon}{4}\right\}<\frac{4 \delta}{\varepsilon} .
$$

Indeed, similarly as in the proof of Theorem 2.1 above, suppose $\mathrm{P}\{f<\varepsilon / 4\}=p \geqslant 4 \delta / \varepsilon$. Let $g:=(1 / p) \chi_{\{f<\varepsilon / 4\}}$ which is in $\Gamma$. Because of (7) we have that $\varepsilon / 4 \leqslant \mathbf{E}_{\mathbf{P}}(f g)=$ $\mathbf{E}_{\mathbf{P}}\left(f \chi_{\{f<\varepsilon / 4\}}\right) / p<\varepsilon / 4$, a contradiction, proving (8).

Using superscripts again we see that we found a sequence of 1-admissible integrands $\left(H^{n_{k}}\right)$ such that

$$
\lim _{k \rightarrow \infty} \mathbf{P}^{n_{k}}\left\{\left(H^{n_{k}} \cdot S^{n_{k}}\right)_{\infty} \geqslant \frac{\varepsilon}{4}\right\} \geqslant \lim _{k \rightarrow \infty} \mathbf{P}^{n_{k}}\left\{f^{n_{k}} \geqslant \frac{\varepsilon}{4}\right\}=1
$$


since $\delta_{k} \rightarrow 0$. Hence the sequence $\left(H^{n_{k}}\right)_{k} \geqslant 1$ admits AA2, a contradiction.

$\mathrm{C}$ on struction of $\mathrm{Example} 2.1$. For $n$ and $1 \leqslant j \leqslant n$ define the random variable $f^{n, j}$ on a suitable base $\left(\Omega^{n}, \mathcal{F}^{n}, \mathbf{P}^{n}\right)$ by

$$
f^{n, j}=\left\{\begin{array}{llll}
1 & \text { on } & A^{n, j}, & \mathbf{P}^{n}\left(A^{n, j}\right)=1-2^{-(j+2)}-2^{-(n+1)}, \\
-2^{-j} & \text { on } & B^{n, j}, & \mathbf{P}^{n}\left(B^{n, j}\right)=2^{-(j+2)} \\
-2^{j} & \text { on } & C^{n, j}, & \mathbf{P}^{n}\left(C^{n, j}\right)=2^{-(n+1)}
\end{array}\right.
$$

such that $\left(f^{n, j}\right)_{j=1}^{n}$ are independent. The process $S^{n}$ is then defined as $S_{0}^{n}=0, S_{1}^{n}=$ $\left(f^{n, 1}, \ldots, f^{n, n}\right)$. Moreover we define the filtration: $\mathcal{F}_{0}^{n}=\left\{\varnothing, \Omega^{n}\right\}, \mathcal{F}_{1}^{n}=\sigma\left(f^{n, 1}, \ldots, f^{n, n}\right)$.

NAA2 is satisfied. Indeed, otherwise there is some $c>0$ such that for each $\varepsilon>0$ there is $n \in \mathbf{N}$ and a 1-admissible integrand such that

$$
\mathbf{P}^{n}\left\{\left(H^{n} \cdot S^{n}\right)_{1} \geqslant c\right\} \geqslant 1-\varepsilon .
$$

We shall show that for $\varepsilon$ small enough this leads to a contradiction. Indeed, in view of the triviality of $\mathcal{F}_{0}^{n}$, we may write $\left(H^{n} \cdot S^{n}\right)_{1}=\sum_{j=1}^{n} h^{n, j} f^{n, j}$ for some real numbers $\left(h^{n, j}\right)_{j=1}^{n}$. We will break the random variable $\left(H^{n} \cdot S^{n}\right)_{1}$ into three pieces $g_{1}^{n}+g_{2}^{n}+g_{3}^{n}$ :

$$
g_{1}^{n}=\sum_{\left\{j \leqslant n: h^{n, j \leqslant 0\}}\right.} h^{n, j} f^{n, j} .
$$

We remark that $\mathbf{P}^{n}\left\{g_{1}^{n} \leqslant 0\right\} \geqslant 1-\sum_{j=1}^{n} 2^{-(j+2)}-n / 2^{n+1} \geqslant \frac{1}{2}$. For $j_{0} \in \mathbf{N}$ to be specified below, let $g_{2}^{n}=\sum_{\left\{j \leqslant j 0: h^{n, j}>0\right\}} h^{n, j} f^{n, j}$ and remark that $\mathbf{P}^{n}\left\{g_{2}^{n} \leqslant 0\right\} \geqslant$ $\prod_{j=1}^{j_{0}} 2^{-(j+2)} \geqslant 2^{-j_{0}^{2}-2 j_{0}}$. As regards the third part $g_{3}^{n}=\sum_{\left\{j_{0}<j \leqslant n: h^{n, j}>0\right\}} h^{n, j} f^{n, j}$, we note that in view of the 1-admissibility of $H^{n}$ and the independence of the $\left(f^{n, j}\right)_{j=1}^{n}$ we have $h^{n, j} \leqslant 2^{-j}$ (for $h^{n, j}>0$ ) so that

$$
g_{3}^{n} \leqslant \sum_{j=j_{0}+1}^{n} 2^{-j} \leqslant 2^{-j_{0}} .
$$

Now choose $j_{0} \in \mathbf{N}, j_{0} \geqslant 3$, such that $2^{-j_{0}}<c / 2$. If $\mathbf{P}^{n}\left\{\left(H^{n} \cdot S^{n}\right)_{1} \geqslant c\right\} \geqslant 1-\varepsilon$ we have that $\mathbf{P}^{n}\left\{g_{1}^{n}+g_{2}^{n} \geqslant c / 2\right\} \geqslant 1-\varepsilon$. On the other hand

$$
\mathbf{P}^{n}\left\{g_{1}^{n}+g_{2}^{n} \leqslant 0\right\} \geqslant \mathbf{P}^{n}\left\{g_{1}^{n} \leqslant 0\right\} \mathbf{P}^{n}\left\{g_{2}^{n} \leqslant 0\right\} \geqslant 2^{-j_{0}^{2}-2 j_{0}-1} \geqslant 4^{-j_{0}^{2}},
$$

a contradiction for $\varepsilon$ small enough, finishing the proof.

We prove now the second part of the assertion in Example 2.1. Suppose that $\left(Q^{n}\right)_{n} \geqslant 1$ is a sequence with $Q^{n} \in \mathcal{M}^{e}\left(\mathbf{P}^{n}\right)$ for all $n$ and $\left(Q^{n}\right)_{n \geqslant 1} \diamond\left(\mathbf{P}^{n}\right)_{n \geqslant 1}$. Since $Q^{n}$ is a martingale measure we must have, for $j=1, \ldots, n$,

$$
0=\mathbf{E}_{Q^{n}}\left(f^{n, j}\right)=Q^{n}\left(A^{n, j}\right)-2^{-(j+1)} Q^{n}\left(B^{n, j}\right)-2^{j+1} Q^{n}\left(C^{n, j}\right) .
$$

Since $Q^{n}\left(A^{n, j}\right)+Q^{n}\left(B^{n, j}\right)+Q^{n}\left(C^{n, j}\right)=1$ (for each $j$ ), we see that

$$
Q^{n}\left(B^{n, j}\right)=\frac{1-\left(2^{(j+1)}+1\right) Q^{n}\left(C^{n, j}\right)}{1+2^{-(j+1)}}
$$

Since $\left(Q^{n}\right)_{n \geqslant 1} \triangleleft\left(\mathbf{P}^{n}\right)_{n \geqslant 1}$ we have that $Q^{n}\left(C^{n, j}\right) \rightarrow 0$ for each fixed $j$. Hence, for each fixed $j, Q^{n}\left(B^{n, j}\right)$ tends to $\left(1+2^{-(j+1)}\right)^{-1}=1-2^{-(j+1)} /\left(1+2^{-(j+1)}\right)$. Choosing an increasing sequence $\left(n_{j}\right)_{j=1}^{\infty}$ such that

$$
Q^{n_{j}}\left(B^{n_{j}, j}\right) \geqslant 1-\frac{2^{-j}}{1+2^{-(j+1)}}
$$

we arrive at a contradiction as $\mathbf{P}^{n_{j}}\left(B^{n_{j}, j}\right)$ tends to zero. 


\section{REFERENCES}

1. Ansel J. P., Stricker $C$. Couverture des actifs contingents. - Preprint, 1992.

2. Delbaen $F$. Representing martingale measures when asset prices are continuous and bounded. - Math. Finance, 1992, v. 2, p. 107-130.

3. Delbaen $F$., Schachermayer $W$. Arbitrage and free lunch with bounded risk for unbounded continuous processes. - Math. Finance, 1994, v. 4, p. 343-348.

4. Delbaen $F$., Schachermayer $W$. A general version of the fundamental theorem of asset pricing. - Math. Ann., 1994, v. 300, p. 463-520.

5. Delbaen $F$., Schachermayer $W$. The no arbitrage property under a change of numéraire. - Stochastics and Stoch. Reports, 1995, v. 53, p. 213-226.

6. Duffie D., Huang C. F. Multiperiod security markets with differential information. J. Math. Economics, 1986, v. 15, p. 283-303.

7. Émery $M$. Compensation de processus non localement intégrable. - Lect. Notes in Math., 1980, v. 784, p. 152-160.

8. Harrison $M$., Kreps $D$. Martingales and arbitrage in multiperiod security markets. J. Econom. Theory, v. 20, p. 381-408.

9. Harrison M., Pliska S. Martingales and stochastic integrals in the theory of continuous trading. - Stoch. Process. Appl., 1981, v. 11, p. 215-260.

10. Кабанов Ю. М., Крамков Д. О. Большие финансовые рынки: асимптотический арбитраж и контигуальность. - Теория вероятн. и ее примен., 1994, т. 39, в. 1, c. $222-228$.

11. Kreps $D$. Arbitrage and equilibrium in economies with infinitely many commodities. - J. Math. Econom., 1981, v. 8, p. 15-35.

12. Schachermayer $W$. Martingale measures for discrete time processes with infinite horizon. - Math. Finance, 1994, v. 4, p. 25-56.

13. Stricker C. Arbitrage et lois de martingales. - Ann. Inst. H. Poincaré, 1990, v. 26, p. $451-460$.

14. Yor $M$. Sous-espaces denses dans $L^{1}$ ou $H^{1}$ et représentation des martingales. Lect. Notes in Math., v. 649, p. 265-309.

Поступила в редакцию

25.VIII.1994

$1996 \Gamma$

LIN ZHENGYAN*

\section{A SELF-NORMALIZED CHUNG TYPE LAW OF THE ITERATED LOGARITHM ${ }^{1 \text { ) }}$}

В [3] установлен закон повторного логарифма, в котором использована неклассическая нормировка. В данной статье получен закон повторного логарифма в форме Чжуна, обобщающий результат [3].

Ключевые слова и фразы: закон повторного логарифма в форме Чжуна, область притяжения нормального закона.

*Department of Mathematics, Hangzhou University, Zhejiang, Hangzhou, 310028, P. R. China.

${ }^{1)}$ Project supported by the National and Zhejiang Provincial Natural Science Foundations of China. 